\title{
Ciência e ancestralidade na Colômbia: Racismo epistêmico sob o disfarce de cientificismo
}

\author{
Science and ancestry in Colombia: Epistemic racism under the \\ guise of scientism
}

Anny Ocoró Loango*

\begin{abstract}
Resumo - Nos últimos anos, a participação de povos indígenas e afrodescendentes no ensino superior e em instituições científicas tornouse uma questão relevante nas universidades da América Latina. Na Colômbia, a polêmica em torno de Mabel Torres - a primeira-ministra negra de Ciência e Tecnologia da história do país - não pode ser analisada criticamente sem relacioná-la a essas discussões. Este artigo torna visível a maneira como o racismo estrutural e epistêmico está presente nesta polêmica; mostra como a demanda por conhecimento comunitário, popular ou ancestral aparece aqui como uma barreira para que povos indígenas e afrodescendentes possam acessar, representar e gerenciar espaços de liderança científica. Também argumenta-se que o embranquecimento aparece como uma condição para assumir a representação em espaços em que se supõe que a negritude não existe. Concluímos que, mais além do dilema epistêmico entre ciência ou ancestralidade, o olhar de uma ciência em diálogo com o conhecimento ancestral de comunidades negras e indígenas, fundamental para o desenvolvimento de territórios negros, na Colômbia, parece estar desaparecendo.
\end{abstract}

Palavras-chave: racismo epistêmico; ciência e ancestralidade; afrocolombianos/as; racismo estrutural.

\begin{abstract}
In recent years, the participation of indigenous and Afrodescendant peoples in higher education and in scientific institutions has become a relevant issue in universities in Latin America. In Colombia, the controversy surrounding Mabel Torres - the first black Minister of Science and Technology in the country's history - cannot be analyzed critically without relating it to these discussions. This article makes visible the way in which structural and epistemic racism is present in this controversy. It shows how the demand for community, popular, or ancestral knowledges appear as a barrier for indigenous and Afro-descendent peoples to access, represent, and manage positions of scientific leadership. It is also argued that whitening appears to be a condition for taking up representation in spaces where it is assumed that blackness does not exist. We conclude that, beyond the epistemic dilemma between science and ancestry, the viewpoint of a science in dialogue with the ancestral knowledge of black and indigenous communities, which is fundamental to the development of black territories in Colombia, seems to be disappearing. Keywords: epistemic racism; science and ancestry; Afro-Colombians; structural racism.
\end{abstract}

\footnotetext{
* Doutora. em Ciências Sociais. Professora/investigadora da Universidad Nacional de Tres de Febrero (UNTREF) e Flacso, Argentina. E-mail:aoloango@untref.edu.ar. ORCID: https://orcid.org/0000-0001-5814-2368.
} 


\section{Introdução}

Em 5 de dezembro de 2019, o presidente da República da Colômbia assinou o decreto pelo qual o Ministério da Ciência, Tecnologia e Inovação foi criado, com a Lei no 1951, de 2019. Este é o órgão da administração pública que elabora e administra as políticas e programas do Sistema Nacional de Ciência, Tecnologia e Inovação (SNCTI) da Colômbia. De acordo com o artigo 2 da Lei no 1951, de 2019, este ministério tem, entre alguns de seus objetivos: formular a política pública do país em ciência, tecnologia e inovação; estabelecer estratégias para o avanço do conhecimento científico, o desenvolvimento sustentável, ambiental, social, cultural e a transferência e apropriação social de ciência, tecnologia e inovação para a consolidação de uma sociedade baseada no conhecimento; e promover o desenvolvimento científico, a tecnologia e a inovação da nação, programadas na Constituição Política de 1991 e no Plano Nacional de Desenvolvimento, de acordo com as diretrizes delineadas pelo governo nacional, entre outras.

A criação desse ministério foi feita de acordo com as recomendações da Missão Internacional de Sábios, que havia sido estabelecida com o objetivo de propor medidas plausíveis para conferir vitalidade a uma área altamente negligenciada no país. Um exemplo evidente disso é o fato de a Colômbia vir destinando para a área de ciência e tecnologia menos de $0,5 \%$ do seu PIB, um dos números mais baixos da região. Segundo o Observatorio Colombiano de Ciencia y Tecnología (OCYT, 2017, p. 12):

la inversión actual que registra el país es particularmente baja para los patrones internacionales, especialmente en I+D. El informe nos indica que nuestra inversión en I+D en 2015, del 0,29\% del PIB, fue muy inferior al promedio de la OCDE, del $2,38 \%$, e incluso del promedio latinoamericano, del $0,70 \%$, un registro por lo demás bajo para los patrones internacionales. No solamente nos encontramos muy por debajo de Brasil, el líder latinoamericano en este campo, sino también de varios otros países de la región (Argentina, Costa Rica, Chile, Ecuador, México y Uruguay.

Em 30 de dezembro, o presidente colocou a cientista afro-colombiana Mabel Gisela Torres à frente do novo Ministério da Ciência, Tecnologia e Inovação em Colômbia. Foi a primeira vez que um ministério foi criado para esta área e isto também mostrou outro aspecto relevante: este ministério foi presidido por uma mulher negra, a primeira afro-descendente a ocupar este cargo neste país.

No ato de sua nomeação, a ministra Mabel Torres declarou: "Meu caminho para a ciência é abrir oportunidades ligadas ao território, porque Bahía Solano me ensinou que vivemos em abundância e temos que criar 


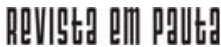

\} CIÊNCIA E ANCESTRALIDADE - LOANGO, A. O. \}

DOI: $10.12957 / R E P .2020 .52012$

um universo melhor"1. Sobre a importância de valorizarmos o território, ela também falou que "todo esse trabalho realizado no território pode contribuir para a transformação social desse país. Hoje me comprometo a contribuir para esta transformação social" (VARGAS, 2019).

Ao falar sobre o território, a ministra o inclui como parte da transformação social de que necessita a Colômbia. Ela também entende que a ciência está ligada ao desenvolvimento do território e das comunidades. Por esse motivo, em sua administração, ela propôs mobilizar:

[...] Uma Colômbia conectada ao mundo, uma Colômbia mais competitiva e avançada em sua produção, uma Colômbia alimentada pelo conhecimento territorial ancestral, uma Colômbia na vanguarda de processos de inovação plurais e inclusivos [...] de gestão do conhecimento, tendo a tecnologia como principal insumo para melhorar a qualidade de vida através do acesso ao mais alto nível de educação e formação científica. ${ }^{2}$

\section{O que sabemos sobre Mabel Torres?}

Mabel Torres nasceu em Bahía Solano, Chocó, em 1972. Estudou biologia, química e obteve um mestrado em microbiologia na Universidad del Valle (Cali). Doutorou-se em ciências biológicas pela Universidade de Guadalajara, México, onde também fez um pós-doutorado em sistemática de fungos. Ela é pesquisadora de ciências naturais preocupada em construir um desenvolvimento com sustentabilidade ambiental, que leve em consideração o conhecimento ancestral das comunidades negras. Possui inúmeros reconhecimentos nacionais e internacionais. Recentemente, manifestou seu desacordo com o uso de glifosato e fracking na Colômbia. Isso gerou críticas de membros do partido do governo ${ }^{3}$.

Em 2019, foi convocada para integrar a "Missão Internacional dos Sábios", que reuniu acadêmicos, intelectuais e artistas de renome de diferentes áreas para contribuir com o desenho de políticas públicas que definem as diretrizes do país para educação, ciência e tecnologia. Cabe ressaltar, porém, que a missão dos Sábios foi criada durante o govervo do presidente Iván Duque, em 2019. Para construir as políticas de Ciência e Tecnologia do país, este grupo de pesquisadores propôs oito focos de trabaIho: 1. Tecnologias convergentes (nano, informação e cognotecnologia) e indústrias 4.0. 2. Indústrias culturais e criativas. 3. Energia sustentável. 4. Biotecnologia, meio ambiente e bioeconomia. 5. Recursos oceânicos e hidrobiológicos. 6. Ciências sociais e desenvolvimento humano com equi-

\footnotetext{
${ }^{1}$ Devemos trabalhar com juventude, 12 de janeiro de 2020.

${ }^{2}$ Defesa da ministra, feita em 20 de janeiro de 2020.

${ }^{3}$ Veja na revista semanal as declarações dos membros do Centro Democrático: https://www.semana.com/nacion/ articulo/uribistas-critican-fuertemente-a-la-nueva-minciencia/647204.
} 


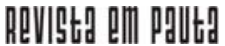

\} CIÊNCIA E ANCESTRALIDADE - LOANGO, A. O. \}

DOI: $10.12957 /$ REP.2020.52012

dade. 7. Ciências da vida e da saúde. 8. Ciências básicas e espaciais. Porém, apesar de o nome da iniciativa ser "Missão dos Sábios", no masculino, dos 47 especialistas, 15 eram mulheres. Também deve-se notar que há apenas um indígena no grupo - o renomado artista da comunidade Inga, Carlos Jacanamijoy - e uma única pessoa de ascendência africana: a Doutora Mabel Torres.

Em 2012, Mabel retornou a Colômbia e ocupou o cargo de diretora executiva do Centro de Pesquisa e Inovação Bioinnova na Universidade Tecnológica Diego Luis Córdoba de Chocó. Referindo-se à sua decisão de retornar a Chocó, ela declarou: "para mim, retornar é cumprir um ciclo de vida em que penso em tudo que minha região me deu" (La Silla Vacía, 2019).

\section{Viver com o racismo estrutural}

Chocó é um dos departamentos mais pobres de Colômbia. Lá, o racismo estrutural, a violência armada e o tráfico de drogas causaram estragos. É também um dos departamentos com a maior população afrodescendente (DANE, 2005). Essas populações foram escravizadas pela atividade de extração de minas de ouro durante os séculos XVII e XVIII (COLMENARES, 1979). Ademais, de acordo com Dane (2005), quatro departamentos concentram $57,59 \%$ das comunidades negras e afro-colombianas. No departamento de Valle del Cauca vive 25,53\% da população (1.090.943 pessoas). Em seguida, o Departamento de Antioquia aparece com 13,88\% (593.174 pessoas), Bolívar com 11,50\% (491.364 pessoas) e, finalmente, colide com $6,69 \%$ (285.964 pessoas). Esses quatro departamentos concentram a população desse grupo étnico. Neste censo, a população total do grupo étnico é $10,31 \%$ da população total da Colômbia. Este artigo não inclui os dados deste censo, porque houve uma redução drástica na população afro-descendente, que tem sido amplamente criticada por vários setores. ${ }^{4}$

Segundo Dane (2019), em 2018 esse departamento concentrou a maior porcentagem de pessoas em situações de pobreza multidimensional $(45 \%$ 1). Se a taxa de pobreza for avaliada levando em consideração o acesso ao trabalho, esses valores serão dobrados. Por exemplo, no mesmo ano, "as maiores privações por família no departamento de Chocó foram encontradas nos indicadores: trabalho informal com 90,3\%, sem acesso a fontes de água melhoradas com $67,0 \%$ e disposição inadequada de excrementos. Com 65,5\%" (DANE, 2019, p.5).

Em relação ao campo educacional, Chocó apresenta fortes desvantagens. O analfabetismo é de $25,6 \%$, enquanto a média nacional é de

${ }^{4}$ Para expansão adicional, consulte: https://www.eltiempo.com/colombia/otras-ciudades/el-error-del-dane-que-borrodel-mapa-a-1-3-millones-de-afros-436936. 


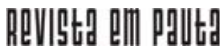

\} CIÊNCIA E ANCESTRALIDADE - LOANGO, A. O. \}

DOI: $10.12957 /$ REP.2020.52012

9,5\%. O atraso escolar registra 40,3\%, em comparação com 28,6\% em todo o país. A porcentagem de famílias com baixa escolaridade (BLE), que em nível nacional é de 43,8\%, em Chocó, é de 62,9\% (DANE, 2019, p. 5).

Neste contexto, o anúncio de uma mulher afro-descendente de Chocó para presidir o primeiro Ministério da Ciência, Tecnologia e Inovação é, sem dúvida, uma excelente notícia, especialmente em um país racista, conservador e patriarcal como a Colômbia. O mesmo vale para uma região predominantemente negra, pobre e punida pelo racismo institucional, pelos gupos armados e pela apatia do Estado.

Mabel Torres representa esses setores. Ela se fez por si mesma e com sua própria força, superando os obstáculos do racismo estrutural e do racismo institucional, dois tipos de racismo aos quais essas populações foram submetidas pelo Estado. Esse problema não é recente, mas, pelo contrário, acompanha a história de Chocó desde a vida colonial. Como Peter Wade (1990, p. 129) bem aponta:

[...] Para a sociedade colonial, Chocó era vista como uma região selvagem, inóspita, perigosa, destinada a ser habitada apenas por indígenas e negros, vista igualmente como primitiva e 'selvagem', enquanto a população branca usava a região e seu povo para a extração de recursos naturais.

A Colômbia se definiu como um país mestiço, que segue silenciando e apagando a existência de povos indígenas e afrodescendentes que fazem parte de sua identidade. De fato, a referência ao "mestiço" em Colômbia está relacionada ao clareamento e não à valorização ou continuidade de traços negros ou indígenas. Misturar significa perder as marcas da cor e da etnia.

Misturar é perder os traços da africanidade. Isso pode ser interpretado no fato de que "a ideologia dominante entende a Colômbia como uma nação em progresso, como um país com a trajetória de superação de seu passado 'primitivo', negro e indígena, em busca de um futuro mais 'civilizado' um futuro mais branco" (WADE, 1990, p. 130).

\section{Ciência ou ancestralidade: além do dilema epistêmico}

Pouco depois de seu nome ter sido escolhido para ficar à frente do ministério e de ter assumido o cargo de ministra, foram publicados, em jornais colombianos reconhecidos, artigos que demonstraram a insatisfação de diferentes setores com as palavras que Mabel Torres disse no programa Los Informantes, alguns meses antes de ocupar o cargo.

No vídeo-documentário intitulado Mábel Torres, uma sábia chocoana que quer modernizar Colômbia, é analisada a trajetória de vida da ministra e o trabalho de pesquisa que ela, como pesquisadora, realiza há 


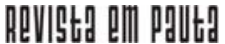

\} CIÊNCIA E ANCESTRALIDADE - LOANGO, A. O. \}

DOI: $10.12957 /$ REP.2020.52012

vários anos com um fungo chamado ganoderma. Neste documentário, Mabel expressa: "fizemos alguns testes, de fato, para fazer uma bebida líquida funcional com ganodermas e outros extratos de frutas do Pacífico, e essa bebida foi tomada por alguns pacientes e tivemos casos positivos de resolução" (LOS INFORMANTES, 2019). Foi graças a essa pesquisa que Mabel Torres ganhou a bolsa Mulher Científica da Unesco.

Curiosamente, a polêmica começou com a publicação do jornal El Espectador, em 10 de janeiro, em um artigo assinado pelo jornalista Pablo Correa (2020), intitulado: Promova uma bebida sem evidência científica. O Ministro da Ciência e sua dúbia promessa contra o câncer. Neste artigo, as palavras de Mabel de agosto de 2019 são retomadas na entrevista documental acima mencionada. $\mathrm{O}$ artigo começa comparando sua carreira à do renomado cientista Rodolfo Llinás. É assim que o jornalista coloca:

[...] Rodolfo Llinás publicou quase 400 artigos ao longo de sua vida nas melhores revistas científicas do mundo, e o currículo de Torres lista 21, 10 deles na revista institucional de sua própria universidade, a U. Tecnológica del Chocó, o programa revelou-se um bom perfil de uma mulher que vem percorrendo os caminhos difíceis e quase sempre ingratos da pesquisa na Colômbia. Exceto por um detalhe. [...] A única publicação delineada em seu currículo que vai além de um esforço taxonômico da ganoderma, cujo autor principal é Carlos Pérez, da Universidade de Córdoba, e coautor, apareceu em 2016 em uma revista cubana e corresponde a um experimento para avaliar as atividades antioxidantes da ganoderma no tratamento da leishmaniose. Mas, como os próprios autores reconhecem, não tiveram a mesma sorte que esperavam: 'o extrato etanólico de Ganoderma sp. não mostrou atividade leishmanicida, um fator possivelmente associado à ausência de compostos heterocíclicos de nitrogênio, que são os que estão comumente relacionados a esse tipo de atividade'. Sobre a relação entre ganoderma e algum tipo de câncer, a ministra não publicou nada. Tal como acontece com muitos outros compostos na medicina tradicional, é frequentemente mencionado que eles podem ter algum benefício, geralmente para um grande número de doenças. Ao ganoderma, a cultura popular também atribui benefícios no tratamento de doenças cardíacas coronárias, arteriosclerose, hepatite, artrite, nefrite, bronquite, hipertensão, câncer e úlceras gástricas. $O$ impacto de sua pesquisa, um indicador importante entre os cientistas, porque mostra o interesse que ele desperta em sua própria comunidade, é baixo. Ao pesquisar no banco de dados Scopus, apenas cinco documentos com seu nome aparecem, que foram citados 28 vezes por 22 documentos. Seu índice de impacto, conhecido como índice $\mathrm{H}$, é quatro. Quando comparado a alguém da mesma área que Inge Armbrecht, diretor da pós-graduação em biologia científica da Faculdade de Ciências Exatas e Naturais da Universidade do Vale, este pesquisador registra 33 documentos citados 779 vezes em 687 documentos e Índice $\mathrm{H}$ de 9. Elena Stashenko, diretora do Centro Nacional de Pesquisa em Agroindustrialização de Espécies de Plantas Medicinais Aromáticas e Tropicais da Universidade Industrial de San- 
tander (Bucaramanga), que explora os usos potenciais da biodiversidade colombiana há quase 30 anos, é autora de 161 documentos e seu índice H é 31. Sua produção acadêmica foi citada 3539 vezes em 2789 documentos. O nome de Mabel não aparece na lista dos 800 pesquisadores colombianos mais citados no portal Webometrics (que usa o índice H calculado pelo Google Scholar). Stashenko ocupa o 35 lugar. (BOGOTÁ, 1934, n. p. - Grifo nosso).

O jornalista questiona porque, em sua opinião, as publicações da ministra e citações em seus artigos são escassas em comparação com as de Rodolfo Llinás. Este artigo, além de questionar sua ética profissional e sua carreira acadêmica, torna invisível em sua análise as limitações e os obstáculos que o racismo estrutural impõe às populações negras da Colômbia e o peso que tem em suas carreiras educacionais e profissionais. Além disso, o jornalista está alarmado com o fato de muitos dos artigos da ministra serem publicados, não nas "melhores revistas científicas do mundo", mas em publicações da Universidade Tecnológica de Chocó. Isso é usado aqui não apenas para prejudicar o trabalho dela, mas também para desqualificar uma pequena universidade de uma das regiões mais pobres e com população majoritariamente negra de Colômbia.

Pablo Correa (2020, p. 1 - grifos nossos) segue se concentrando nas declarações da pesquisadora sobre a ganoderma:

Na frente das câmeras, como já havia feito em outros ambientes, disse que, depois de estudar fungo do gênero ganoderma por vários anos, e ao retornar a Chocó, decidiu elaborar uma 'bebida líquida funcional com ganoderma e outros extratos de frutas do Pacífico. Esta bebida foi tomada por alguns pacientes e tivemos casos positivos de resolução em câncer de colo do útero, mama e cérebro, principalmente'. [...]. No currículo que Mabel Torres apresentou à Colciencias - instituição que se tornou Ministério da Ciência e que ela atualmente preside, foram informados 21 artigos científicos. Sete deles, diretamente relacionados à ganoderma e outros 11 com fungos em geral. Seu trabalho com esse fungo demostra que ela alcançou um estágio valioso, mas muito básico, de conhecimento: são estudos taxonômicos, ou seja, classificação botânica. Suas publicações acadêmicas mostram o esforço que ela fez como pesquisadora para coletar diferentes espécies de fungos na América e a necessidade de classificá-las e estudá-las com maior profundidade. [...].

Esses comentários, com um evidente tom condenatório e tendencioso, questionam a ética profissional de Mabel Torres e buscam mostrar que havia uma falta de rigor em suas investigações. Com base no artigo publicado pelo jornalista, diferentes organizações científicas rejeitaram as declarações e resultados de Mabel, apelando fundamentalmente ao cumprimento dos protocolos científicos. De acordo com as informações coletadas pelo jornal colombiano El País, da Colombia, a Associação 


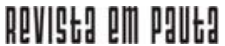

\} CIÊNCIA E ANCESTRALIDADE - LOANGO, A. O. \}

DOI: $10.12957 /$ REP.2020.52012

Colombiana de Faculdades Médicas se manifestou sobre o ocorrido, lamentando: "a tarefa de como fazer ciência em nosso país foi deixada nas mãos da pseudociência". Sobre esta questão, o presidente da Ascofame disse:

Acreditamos que a pesquisa é o fio condutor da formação das pessoas em saúde neste país e no mundo. E se você não tem o rigor que sempre teve, porque alguém tem o poder governamental e desconfia do método científico, mas também se rebela contra a ciência, acreditamos que ela não pode ser o ministro deste país" (CABRERA, 2020 grifos nossos).

Apesar de tudo isso, a "Missão dos Sábios" não emitiu nenhum comunicado sobre a polêmica.

Como Bourdieu (1998) nos mostrou bem, o capital cultural, o capital social e as desigualdades sociais de origem, entre outros, condicionam as trajetórias de vida, mas aqui eles parecem não ter relevância na avaliação do trabalho desenvolvido por Mabel. Desde a década de 1970, as contribuições clássicas de Young (1971), Bernstein (1989) e Bourdieu (1970), no campo da sociologia da educação, contribuíram para tornar visível a cumplicidade estrutural que a escola teve na reprodução de desigualdades sociais. Como bem afirma Dubet (2006, p. 15), "se a igualdade de oportunidades não foi alcançada, não é apenas porque a sociedade é desigual, mas porque o jogo escolar é mais favorável para os mais favorecidos". O mesmo pode ser pensado no campo científico: é sem dúvida "mais favorável para os mais favorecidos".

É essencial destacar que os/as pesquisadores/as, com os quais se compara a trajetoria de Mabel Torres, provêm de outros setores socioeconômicos, de outras realidades culturais. Ou seja: não são atravessados pelos problemas de raça e classe vividos por Mabel. Eles tiveram acesso a outro capital social e cultural. Ciência não é prática asséptica. O campo científico está cheio de disputas, tensões, alianças e atores que desejam construir sua própria hegemonia no campo e que controlam as regras do jogo. A inserção nesses espaços não é uma tarefa fácil. Não se trata apenas de mérito ou êxito na carreira profissional, mas também de poder, mais especificamente de relações de poder e dominação das quais o campo científico não está isento.

Como Bourdieu (2002, p. 9) afirma corretamente,

o campo intelectual, à maneira de um campo magnético, constitui um sistema de linhas de força: ou seja, os agentes ou sistemas de agentes que fazem parte dele podem ser descritos como forças que, quando surgem, se opõem e se agregam, dando-lhe sua estrutura específica em um dado momento no tempo".

Em uma entrevista, Walter Mignolo (2003) afirma que, de certa forma, o conhecimento funciona de maneira análoga à economia: baseia- 


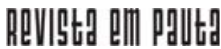

\} CIÊNCIA E ANCESTRALIDADE - LOANGO, A. O. \}

DOI: $10.12957 /$ REP.2020.52012

se na existência de "centros de poder" que são referência em campo e em "regiões subalternas" que dependem do primeiro. Então,

pode-se acrescentar que essa relação de superioridade também é atravessada por uma questão racial: o conhecimento é racializado. [...] Quando o corpo da pessoa que o enuncia é negro, o conhecimento é considerado pseudocientífico, algo que não ocorre quando se trata de 'brancos' que estudam negros. (OCORÓ, 2019, p. 25).

Obviamente, se racializam como inferiores os conhecimentos de cujos corpos, culturas e histórias não são "representativos" da cultura ocidental (FANON, 1973). Essas situações são apenas mais um exemplo do racismo epistêmico presente em nossas sociedades latino-americanas.

A Colômbia é um país com desigualdade estrutural no acesso ao ensino superior. É um país que tem uma dívida histórica no ensino superior com toda a população e, em particular, com grupos indígenas e afrodescendentes. Dificuldades, todas essas, que Mabel Torres teve que superar como mulher, sendo negra nas áreas rurais e proveniente de uma família com recursos limitados. Raça, classe, gênero e ruralidade aparecem aqui como variáveis que não podemos separar de sua experiência e carreira profissional. Na entrevista do programa Los Informantes, Mabel expressou: "Havia outras crianças que eu sabia que nunca deixariam Bahía Solano porque não era economicamente viável, não era possível. Então, toda vez que eu me afastava, era como se estivesse mais perto. Sempre foi com essa convicção que tive que voltar para devolver o que havia aprendido" (LOS INFORMANTES, 2019, n. p.). Ela desafiou o "destino" da privação e da desigualdade a que as populações negras de Colômbia estão sujeitas e, como consequência, agora terá que enfrentar o racismo epistêmico que se aninha em nossas instituições de ciência e tecnologia.

Na palestra do TED: Uma história de amor com ancestralidade, Mabel conta a história de uma menina de sua cidade que foi para perto do pai e disse: "pai! Eles me deixaram uma tarefa sobre uma cientista chamada Mabel Torres". O homem respondeu: "Eu a conheço" - e a garota não acreditou nele. Então, o pai a levou ao laboratório e, dias depois de conhecer o trabalho de Mabel, a garota falou: "Eu pensei que os cientistas eram brancos, homens e ricos" ${ }^{\prime \prime}$. Não podemos negar o quanto é importante para uma mulher negra, doutora em ciências, ser a primeira-ministra da Ciência, Tecnologia e Inovação, especialmente em um país onde as comunidades negras, das quais Mabel vem, enfrentam sérias desigualdades sociais e econômicas, bem como problemas agudos de discriminação e racismo. Isso também adquire relevância simbólica, pois contribui para tornar visível a presença negra em locais onde tradicionalmente o conhecimento de uma mulher afrodescendente não aparece e não é valorizado.

${ }_{5}^{5}$ TED da Universidad del Rosario, em 10 de abril de 2018. Disponível em: https://www.youtube.com/watch?v=1DXJFcGp6k. Acesso em: 4 fev. 2020. 


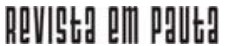

\} CIÊNCIA E ANCESTRALIDADE - LOANGO, A. O. \}

DOI: $10.12957 /$ REP.2020.52012

Infelizmente, a ideologia racista, que construiu uma imagem da população negra, desprovida de capital social e cultural, instaurada pelo colonialismo, ainda continua. Além disso, ele opera hierarquizando e limitando diariamente o acesso a oportunidades.

Curiosamente, no Sistema Nacional de Ciência, Tecnologia e Inovação (SNIES) da Colômbia, não existem dados oficiais sobre mulheres negras de ascendência africana que tenham doutorado. De acordo com o Sistema Nacional de Informação do Ensino Superior do Ministério da Educação, entre 2010 e 2017, apenas 40\% das mulheres possuem doutorado e em áreas tradicionalmente "femininas". A autodeclaração étnico-racial não é uma variável usada nesses registros e esses dados são levados em consideração em muito poucas universidades. Essa mesma situação é apresentada nos dados da Colciencias, Departamento Administrativo de Ciência, Tecnologia e Inovação de Colômbia, onde esta variável também não é considerada. Isso pode ser sustentado "pelo pouco interesse por parte dos governos em estudar essas questões com profundidade, pois mostraría dados precisos relacionados com as discriminações que persistem em seus sistemas e, em caso de revisão internacional, estariam malvistos" (TOMASEVSKI, 2020, p. 38). Também pode ser explicado pelo fato de as instituições de ensino superior assumirem a meritocracia como um valor acima das diferenças étnicoraciais e de gênero, quando na realidade essa invisibilidade contra diferenças - que marcam claramente o acesso aos recursos, aos espaço de poder, à educação - ajuda a alimentar os fundamentos do racismo epistêmico.

Os dados estatísticos informados pelo Census 2018 não oferecem indicações separadas, nem por sexo, nem por participação em programas de pós-graduação. Eles afirmam apenas que 14,3\% da população do Narp (negros, afrocolombianos, raizales e quilombolas) possui estudos superiores. A porcentagem no nível nacional é $18,8 \%$ do total nacional. No entanto, de acordo com o censo, apenas 1,8\% das pessoas negras têm pós-graduação.

Mabel Torres é uma pesquisadora negra que, usando a metáfora feminista, conseguiu quebrar o "techo de cristal" 6 . Trata-se de um "teto de vidro racial" que a sociedade impõe a ela por ter vindo de uma região muito pobre, por ser mulher e por ser negra. No vídeo-documentário do programa Los Informantes (2019), Mabel expressou: "Tive que saltar um pouco os estereótipos, antes de ser uma região, porque sou de uma cidade pequena, de ter alguns pais que não eram educados na universidade, além de salvar o estigma e o estereótipo de ser mulher, ser negra". Ela rompeu o teto racial de sua carreira educacional, e deste lugar se posicionou falando sobre territórios e ancestralidade, lembrando-nos que a ciência deve estar a serviço das comunidades. A partir daí, a doutora Torres criou um espaço para si mesma em uma academia branca, principalmente masculina e, em

${ }^{6}$ No feminismo e nos estudos de gênero, "techo de cristal" é uma expressão que significa o limite invisível que a sociedade impõe para a ascensão laboral das mulheres. 


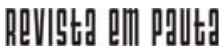

\} CIÊNCIA E ANCESTRALIDADE - LOANGO, A. O. \}

DOI: $10.12957 /$ REP.2020.52012

muitos casos, racista. Lembre-se de que, na América Latina, "a presença de pesquisadores negros em instituições de ensino superior (IES) ainda é minoritária. Entre professores universitários e equipes de pesquisa, eles estão sub-representados e, em muitos casos, sua presença é invisível" (OCORÓ, 2019, p. 18).

Com efeito, "percebe-se, que a presença de 'mulheres negras' no espaço científico ainda é pouco representativa. Enquanto mulheres brancas reivindicam o reconhecimento no universo acadêmico, as mulheres negras caminham com a perspectiva de ingressarem na carreira universitária (EUCLIDES, 2017, p. 55). Para Silva, tanto o racismo quanto o sexismo são dois fatores que explicam a presença limitada de mulheres negras em ambientes acadêmicos (SILVA, 2010). Dessa forma, "[...] à medida que aumentam os níveis de formação, diminui a participação das mulheres a integrar aquele grupo. Por conseguinte, seu número é significativamente inferior nos campos diretivos e de representações de poder no âmbito universitário" (SILVA, 2010, p. 30).

Devemos também enfatizar que há uma acentuada ausência de história e epistemologias negras nos programas acadêmicos das IES. A produção intelectual negra é pouco valorizada ou quase desconhecida nas bibliografias dos programas acadêmicos (OCORÓ, 2019). Além de focar nas afirmações de Mabel Torres, que geraram a polêmica, nosso objetivo é examinar todos os aspectos que envolvem as notícias para tornar visível a maneira como o racismo estrutural e epistêmico está presente neste debate.

\section{Embranquecimento através da ciência. Revelando o racismo epistêmico na Colômbia}

Felizmente, a ministra Dra. Mabel Torres recebeu o apoio da Mesa Nacional de Mulheres Negras-Afro-Colombianas. Na sessão "cartas aos leitores", essas mulheres expressaram:

Como povo negro, estudamos as múltiplas formas de discriminação que existem principalmente nos setores acadêmicos e políticos; como é o caso de El Espectador, que escreveu sobre nossa recém-empossada ministra Mabel Torres Torres e, rapidamente, rouba da ministra uma história que acabou de começar. Te aborrece tanto que uma mulher negra, com respaldo acadêmico, seja sua ministra? (SALAZAR, 2020, n. p.).

Na mesma direção, a Academia Nacional de Medicina, órgão que assessora políticas de saúde e educação médica do governo nacional, aclamou a criação do ministério e foi a favor da superação da polêmica. Em uma declaração, a instituição se posicionou desta maneira: 


\begin{abstract}
A Colômbia, desde este ano, conta com um Ministério de Ciência, Tecnologia e Inovação, por isso a Academia Nacional de Medicina, convida [...] a promover que neste Ministério, e desde o início, são impulsionados, ventilados e apoiados conceitos modernos de ciência, tecnologia, conhecimento e método científico e, no campo da saúde, medicina moderna. Sem desconsiderar ou desrespeitar o conhecimento ancestral ou qualquer outro tipo de pensamento, tenhamos um espírito verdadeiramente propositivo e construtivo. Não é possível frustrar ou desfigurar este Ministério por intermináveis discussões e controvérsias, considerações infelizes e conceitos apoiados por apreciações individuais de pensamento. (REDACCIÓN VIVIR, 2020, n. p.).
\end{abstract}

Os argumentos de muitas pessoas que pediram a renúncia da ministra mostram a desvalorização e, em muitos casos, o desprezo pelo conhecimento tradicional ou ancestral. Nas várias declarações e aparições públicas, mesmo antes de ser nomeada ministra, Mabel Torres expressou total respeito pelo método científico. Ela afirmou: "Eu nunca disse que o método científico não era válido. Nunca renunciei ao método científico, nem incentivei para que isso ocorresse" (EL PAÍS, 2020, n. p.). Ela também fez um chamado para que outras epistemologias sejam recuperadas, a fim de que tenhamos um desenvolvimento mais integral: "o ancestral não é ciência, mas produz conhecimento" (AGUIRRE, 2020, n. p.). Em uma declaração recente, na qual ela responde à controvérsia e aos pronunciamentos de diferentes associações que criticaram suas declarações, a ministra disse:

Durante esses anos de experiência, retroalimentei minha formação como cientista com a análise do conhecimento ancestral e outras formas de produção de conhecimento que me deram novas perspectivas para entender os diferentes desafios que o país enfrenta e suas oportunidades justamente pelo privilégio de contar, conforme destacado no relatório da Missão dos Sábios, com a riqueza que a biodiversidade e a diversidade cultural e étnica, com suas tradições e conhecimentos ancestrais e a heterogeneidade de suas regióes, fazem de Colômbia um país único em seu grande potencial. O relatório final da Missão dos Sábios 2019, do qual eu fazia parte, considera que o conhecimento inclui ciência, humanidades, artes e conhecimento ancestral, e é considerado um ativo fundamental para o desenvolvimento de alternativas novas e criativas para a crise atual. Esses conhecimentos não se encontram isolados, não são estáticos nem imutáveis. Tampoco a ciência ocidental é monolítica, nem está livre de falhas e incertezas. Um começo nessa direção poderia ser o reconhecimento da multiplicidade de epistemologias, lógicas e práticas que estão abaixo da criação e manutenção de diferentes conhecimentos. (TORRES, 2020, p. 1).

Como diferentes autores problematizaram (CASTILLO; CAICEDO, 2008; CASTRO-GÓMEZ, 2007; LANDER, 2000; 2002; MATO, 2008), as universidades e os sistemas de ciência e tecnologia favoreceram o euro- 


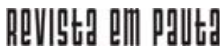

\} CIÊNCIA E ANCESTRALIDADE - LOANGO, A. O. \}

DOI: $10.12957 /$ REP.2020.52012

centrismo como paradigma de formação e pesquisa, legitimando formas hegemônicas de conhecimento, contribuindo para qualificar o conhecimento ancestral ou tradicional como folclórico, exótico, pré-científico ou simplesmente como obstáculos ao conhecimento. O discurso hegemônico eurocêntrico e as relações de poder que esse discurso administra as relações pelas quais o conhecimento e o conhecimento dos povos negros foram subestimados - permitem a reprodução de desigualdades sociais, porque legitima e autoriza apenas uma cultura, uma história, impondo sua superioridade epistêmica, política e histórica à Europa. O caráter excludente e monocultural das universidades, seus modelos de treinamento, pesquisa e relacionamento com populações indígenas e afro-descendentes constituem um dos maiores problemas na relação entre interculturalidade, universidade e sistemas de ciência e técnica. Como bem ressalta a ministra,

na academia e nas universidades, não aprendemos a valorizar o que há por trás das comunidades, porque o conhecimento realmente técnico prevaleceu sobre o conhecimento ancestral [...]. Quando reconhecemos que existe um conhecimento ancestral por trás das coisas, também reconhecemos que a ciência deve contribuir com esse conhecimento ancestral para desenvolver os territórios ${ }^{7}$.

As ciências sociais, durante muito tempo, têm privilegiado o conhecimento produzido na estrutura científica acadêmica e nos paradigmas ocidentais da ciência. Também contribuíram para qualificar o conhecimento acadêmico-científico como "universal", desqualificando e rotulando os modos de produção de conhecimento "indígenas" e afrodescendentes como "locais" (MATO, 2008). A ciência e os métodos de pesquisa são construções sócio-históricas que os paradigmas e visões dominantes tiveram a eficácia de naturalizar e despolitizar, tornando hegemônicas certas formas de conhecimento, assim como também a visão eurocêntrica que as constitui. A hegemonia do conhecimento eurocêntrico prevaleceu ao lado da desapropriação e, em muitos casos, junto com a aniquilação de outras formas de conhecer e habitar o mundo. O racismo epistêmico impõe a superioridade de uma cultura sobre outra, a ponto de assimilar, negar ou suprimir. Esse racismo está relacionado à primazia monocultural, hegemônica ocidental, eurocêntrica e científica, na qual certos conhecimentos tradicionais e culturas foram invisíveis ou inferiorizados.

Nos últimos anos, as visões hegemônicas da ciência, bem como sua visão como um processo linear, unívoco e universal, têm sido questionadas (ÁVILA, 2004). A ciência aparece então como um processo histórico e não como mero acúmulo de conhecimento (KUHN, 1971). Isso é visto como uma prática social condicionada histórica e socialmente, cujo grande triunfo tem sido mostrar uma suposta objetividade e neutralidade do co-

${ }^{7}$ TED da Universidad del Rosario, de 10 de abril de 2018. 


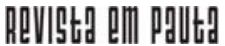

\} CIÊNCIA E ANCESTRALIDADE - LOANGO, A. O. \}

DOI: $10.12957 /$ REP.2020.52012

nhecimento, evitando os debates políticos e sociais dos quais surgiram seus postulados (PIOVANI, 2008). Um dos maiores mitos do pensamento científico é sustentar que o conhecimento científico é capaz de operar sem um sujeito condicionado e situado que o agencie. A ciência é e sempre foi uma construção política, na medida em que é organizada pelos sujeitos. Não existe ciência des-historicizada, sem sujeito e sem contexto.

Os espaços acadêmicos não são estranhos ao racismo que reina na sociedade. A negação dos/as negros/as como sujeitos produtores de conhecimento, bem como o fato de reduzi-los a uma espécie de minoria, é uma forma comum de racismo epistêmico que às vezes passa despercebido. O racismo, arraigado nos espaços acadêmicos, é incapaz de reconhecer o status de igualdade cognitiva do outro, subalterniza seu conhecimento e cultura e contribui para aumentar e reproduzir sua conexão desigual nos campos de produção de conhecimento e estruturas da sociedade (OCORÓ, 2019). Consequentemente, essa racialização do conhecimento deve ser lida em termos estruturais, uma vez que não é produzida apenas por indivíduos ou grupos que assumem as formas de conhecimento dos outros como inferiores, mas é constitutiva da tradição do pensamento ocidental. Precisamente, "o Ocidente é considerado a única tradição legítima de pensamento para produzir conhecimento, e a única com acesso à 'universalidade', 'racionalidade' e 'verdade'. O racismo epistêmico considera o conhecimento 'não ocidental' como inferior ao conhecimento 'ocidental'" (GROSFOGUEL, 2012, p. 54).

Embora seja difícil de acreditar, eles não perdoaram Mabel Torres pelo fato de ela ter falado de ancestralidade, naquele espaço "científico", que opera desqualificando o saber popular. Costuma-se pensar que o conhecimento científico só pode ser realizado apagando as marcas do conhecimento "popular", "tradicional" ou "ancestral". Isso que surge como um requisito para ser aceito dentro do cânon da ciência também é um preconceito arraigado que se tornou naturalizado. Do mesmo modo que nos tempos da colônia e início do período republicano na América Latina, o discurso do branqueamento buscava escapar dos vestígios da africanidade para alcançar uma forma de ascensão social; hoje, se exige que a ministra se desvincule dos saberes negros ancestrais, do conhecimento "não autorizado", para legitimar sua presença naquele espaço. Isso demonstra que o discurso de branqueamento ainda permanece em nossas sociedades.

A ministra deve dissolver suas marcas culturais e étnico-raciais para obter legitimidade naquele espaço, ou seja: deve ser branqueada. Como consequência,

dissociando a localização étnica/racial/de gênero/sexual epistêmica do sujeito falante, a filosofia e a ciência ocidentais podem produzir um mito sobre um conhecimento universal credível que ele cobre, ou seja, disfarça o falante e sua localização epistêmica, geopolítica 
e política do corpo nas estruturas de poder/conhecimento [...]. (GROSFOGUEL, 2006, p. 20-21).

A Mabel Torres é exigido "branquearse" como uma condição para direcionar espaços que se pressupõem estranhos à negritude. Isso revela que mesmo hoje o racismo epistêmico ainda está presente. Se gênero e raça são barreiras ao acesso ao trabalho e à educação na Colômbia, o mesmo acontece com a "ancestralidade" para representar e gerenciar espaços de liderança científica. Além do dilema epistêmico entre ciência ou ancestralidade, o olhar de uma ciência em diálogo com o conhecimento ancestral de comunidades negras e indígenas, que se coloca a serviço do desenvolvimento de territórios negros na Colômbia, parece estar desaparecendo.

\section{Como conclusão}

O caso de Mabel Torres abre as portas para um debate que vem ocorrendo há vários anos em algumas universidades latino-americanas. A partir de seus programas de formação, eles vêm posicionando a necessidade de pensar em processos interculturais, seja por meio de ações afirmativas que deram aos indígenas e afrodescendentes acesso a esses programas, seja por meio de um currículo destinado a promover a educação intercultural. Da mesma forma, a participação de povos indígenas e afrodescendentes se tornou, nos últimos anos, uma questão central nos debates sobre o ensino superior na América Latina, a ponto de ser um dos eixos centrais da Conferência Regional de Educação Superior, realizada na Universidade Nacional de Córdoba em junho de 2018.

Uma visão mais pluralista da ciência, tecnologia e inovação, de acordo com as realidades sociais e culturais da América Latina, tem o desafio de incorporar o conhecimento dos povos indígenas e afrodescendentes nas políticas de ciência e tecnologia, para avançar para sociedades mais equânimes e conscientes de sua história e diversidade. Em outras palavras, trata-se do fato de que cada sociedade não só é capaz de usar o conhecimento e os saberes de todos os grupos étnicos para pensar em seu próprio desenvolvimento, mas também criar alternativas para seu presente e seu futuro. 


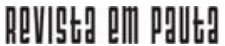

\} CIÊNCIA E ANCESTRALIDADE - LOANGO, A. O. \}

DOI: $10.12957 /$ REP.2020.52012

\section{Referências}

AGUIRRE, F. R. Mabel, la voz y el rostro del naciente Minciencia. El Colombiano, 20 jan. 2020. Disponível em: https://www.elcolombiano.com/ colombia/entrevista-a-mabel-torres-ministra-de-ciencia-FG1 2275981. Acesso em: 23 jan. 2020.

ÁVILA, R. La observación, una palabra para desbaratar y re-significar. Cinta moebio, n. 21, 2004. Disponível em: www.moebio.uchile.cl/21/avila.htm. Acesso em: 12 fev. 2020.

BERNSTEIN, B. Clases, códigos y control, vol. 2. Hacia una teoría de las transmisiones educativas. Madrid: Akal.1989.

BOURDIEU, P. La reproducción. México: Fontamara, 1970.

BOURDIEU, P. Capital cultural, escuela y espacio social. México: Siglo XXI, 1998.

BOURDIEU, P. Campo de poder, campo intelectual. Bueno Aires: Editorial Montressor, 2002.

CABRERA, D. Científicos cuestionan "método" de la ministra de Ciencia para tratar el cáncer. RCN Radio, 14 jan. 2020. Disponível em: https:// www.rcnradio.com/salud/cientificos-cuestionan-metodo-de-la-ministra-deciencia-para-tratar-el-cancer. Acesso em: 15 jan. 2020.

CASTILLO, E.; CAICEDO, J. Indígenas y afrodescendientes en la Universidad Colombiana: nuevos sujetos, viejas estructuras. Cuadernos Interculturales, n. 10, 2008.

CASTRO-GÓMEZ, S. Decolonizar la universidad. La hybris del punto cero y el diálogo de saberes. In: CASTRO-GÓMEZ, S.; GROSFOGUEL, R. (Ed.). El giro decolonial. Reflexiones para una diversidad epistémica más allá del capitalismo global. Bogotá: Siglo del Hombre Editores, 2007.

COLMENARES, G. Popayán: una sociedad esclavista, 1680-1800. Historia económica y social de Colombia, tomo II. Medellín: La Carreta, 1979.

CORREA, P. Promueve una bebida sin evidencia científica. La ministra de Ciencia y su dudosa promesa contra el cáncer. El Espectador, 10 jan. 2020. Disponível em: https://www.elespectador.com/noticias/ciencia/la-ministrade-ciencia-y-su-dudosa-promesa-contra-el-cancer-articulo-899370. Acesso em: 12 jan. 2020.

DANE. Pobreza multidimensional región pacífica (sin incluir Valle del Cauca). Bogotá: Departamento de Énfasis, 2019.

DUBET, F. La escuela de las oportunidades ¿qué es una escuela justa". ED Gedisa, 2006. 


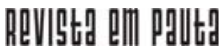

\} CIÊNCIA E ANCESTRALIDADE - LOANGO, A. O. \}

DOI: $10.12957 /$ REP.2020.52012

EL PAÍS. Ministra de Ciencia le sale al paso a la polémica por sus declaraciones sobre el ganoderma. El País, 23 jan. 2020. Disponível em: https:// www.elpais.com.co/colombia/ministra-de-ciencia-le-sale-al-paso-a-la-pole mica-por-sus-declaraciones-sobre-el-ganoderma.html. Acesso em: 25 jan. 2020.

EUCLIDES, M. S. Mulheres negras, doutoras, teóricas e professoras universitárias: desafios e conquistas. Tese (Doutorado em Educação Brasileira) Programa de Pós-Graduação em Educação Brasileira, Centro de Ciencias Humanas, Universidade Federal do Ceará, Ceará, 2017.

FANON, F. Piel Negra. Máscaras Blancas. Editorial Abraxas. Buenos Aires.1973. FIGUEREIDO, A.; GROSFOGUEL, R. Por que não Guerreiro Ramos? Novos desafios a serem enfrentados pelas universidades públicas brasileiras. Ciência e Cultura, v. 59, 2007.

GRANADA, L. Investigación doctoral en proceso: experiencias educativas de mujeres negras afrodescendientes doctoras. Bogotá: Universidad Pedagógica Nacional, 2020.

GROSFOGUEL, R. Islamofobia epistémica y ciencias sociales coloniales. In: MARTÍNEZ, A.; MERLINO (Coord.). Género, raza y poder. Argentina: Eduvim, 2012.

GROSFOGUEL, R. La descolonización de la economía política y los estudios postcoloniales: transmodernidad, pensamiento fronterizo y colonialidad global. Tabula Rasa, (4), 2006, p. 17-46. Disponível em: https:// www.redalyc.org/articulo.oa?id=396/39600402. Acesso em: 01 jul. 2020. KUHN, T. La estructura de las revoluciones científicas (Fondo de Cultura Económica: México). 1971.

LANDER, E. La utopía del mercado total y el poder imperial. Venezolana de Economía y Ciencias Sociales, Caracas, v. 8, n. 2, 2000.

LANDER, E. Eurocentrismo, saberes modernos y la naturalización del orden global del capital. 2002. Mimeo.

LOS INFORMANTES. Mábel Torres, una sabia chocoana que quiere modernizar Colombia. 2019. Disponível em: https://www.youtube.com/ watch?v=ng95Z4i8vK0. Acesso em: 18 jan. 2020.

MATO, D. No hay saber "universal", la colaboración intercultural es imprescindible. Alteridades, v. 18, n. 35, 2008.

OCORÓ, L. A. Entre la emancipación y la descolonización: tensiones luchas y aprendizajes de los/as investigadores/as negros/as en la educación superior. Revista Práxis Educacional, v. 15, n. 32, abr./jun. 2019. Disponível em: https://doi.org/10.22481/praxis.v15i32.5043. Acesso em: 01 fev. 2020.

PIOVANI, J. I. Producción y reproducción de sentidos en torno de lo cuantitativo y lo cualitativo en la sociología. In: COHEN, N.; PIOVANI, J. I. 


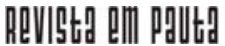

\} CIÊNCIA E ANCESTRALIDADE - LOANGO, A. O. \}

DOI: $10.12957 /$ REP.2020.52012

(Comp.). La metodología de la investigación en debate. La Plata: EdulpEudeba, 2008.

REDACCIÓN VIVIR. Academia Nacional de Medicina se pronunció sobre el caso de la ministra de Ciencia. El Espectador. 2020. Disponível em: https://www.elespectador.com/noticias/ciencia/academia-nacional-demedicina-se-pronuncio-sobre-el-caso-de-la-ministra-de-ciencia-articulo901044. Acesso em: 21 jan. 2020.

SALAZAR, I. L. En respaldo a la ministra Mabel Torres. El Espectador, 15 jan. 2020. Disponível em: https://www.elespectador.com/opinion/enrespaldo-la-ministra-mabel-torres-columna-899737. Acesso em: 18 jan. 2020.

SILVA, J. da. Doutoras professoras negras: o que nos dizem os indicadores oficiais. Perspectiva, v. 28, n. 1, 2010.

SISTEMA NACIONAL Ciencia, Tecnología e Innovación (SNIES) de Colombia. Ministerio de Educación de Colombia. Módulo de consultas: Instituciones de Educación Superior. Disponível em: https://www.mine ducacion.gov.co/sistemasdeinformacion/1735/articles-212400_recurso _23.rar. Acesso em: 03 fev. 2020.

TOMASEVSKI, K. Indicadores del derecho a la educación. Instituto Interamericano de Derechos Humanos, 40, 2004.

TORRES, M. Declaración: Mabel Gisela Torres Torres, Ministra de Ciencia, Tecnología e Innovación, 2020. Disponível em: https://minciencias.gov.co/ sala_de_prensa/declaracion-mabel-gisela-torres-torres-ministra-cienciatecnologia-e-innovacion. Acesso em: 22 jan. 2020.

VARGAS, C. C. Mabel Torres, la primera ministra de Ciencia y los retos que enfrentará. RCN Radio, 30 dez. 2019. Disponível em: https:// www.rcnradio.com/colombia/mabel-torres-la-primera-ministra-de-cienciay-los-retos-que-enfrentara. Acesso em: 05 jan. 2020

WADE, P. El Chocó: una región negra. Boletín Museo del Oro 29: $121-$ $149,1990$.

YOUNG, M. (ed.). Knowledge and control: new directions for the sociology of education. London: Collier Macmillan, 1971.

DOI: $10.12957 /$ rep.2020.52012

Recebido em 15 de maio de 2020.

Aprovado para publicação em 20 de maio de 2020.

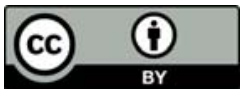

A Revista Em Pauta: Teoria Social e Realidade Contemporânea está licenciada com uma Licença Creative Commons Atribuição 4.0 Internacional. 